\title{
Efeito alelopático do extrato aquoso de sabiá na germinação de sementes de fava ${ }^{1}$
}

\author{
Allelopathic effect of aqueous extract of Mimosa caesalpiniaefolia Benth. in seed \\ germination of Phaseolus lunatus
}

\author{
Elane Grazielle Borba de Sousa Ferreira ${ }^{2 *}$, Valderez Pontes Matos ${ }^{3}$, Lúcia Helena de Moura Sena ${ }^{3}$ e Anna \\ Gorett de Figueiredo Almeida Sales ${ }^{4}$
}

\begin{abstract}
Resumo - O sabiá (Mimosa caesalpiniaefolia Benth.) é uma planta medicinal que pode ser utilizada em sistemas agroflorestais. É empregada na composição de pastagens arbóreas, em faixas entre plantações, para enriquecer capoeiras e ainda pode ser empregada como cerca viva. A fava (Phaseolus lunatus L.) é uma das quatro espécies do gênero Phaseolus exploradas comercialmente, seu consumo é preferencialmente na forma de grãos verdes cozidos ou na forma de conserva. O presente trabalho teve como objetivo verificar o efeito alelopático do extrato aquoso do sabiá sobre a germinação de sementes e crescimento inicial de plântulas de fava. As sementes de fava foram postas para germinar em caixas plásticas, onde foram semeadas entre o substrato vermiculita, e em seguida colocados em germinador a $25^{\circ} \mathrm{C}$ e sob luz contínua. O substrato foi umedecido, com o extrato aquoso de folhas jovens de sabiá, nas concentrações de 25; 50; 75 e 100\%, além da testemunha umedecida apenas com água destilada. As variáveis avaliadas foram: porcentagem, primeira contagem e índice de velocidade de germinação além do comprimento da raiz primária. O delineamento experimental utilizado foi o inteiramente casualizado, com quatro repetições de 25 sementes cada. Os dados obtidos foram submetidos à análise de variância e de regressão polinomial. No estudo da regressão polinomial foi empregada a equação que melhor se ajustou aos dados. Os valores em porcentagem foram transformados em $\operatorname{arc} \operatorname{sen}(\mathrm{n} / 100)^{0,5}$. Conclui-se que as diferentes concentrações do extrato de folhas jovens de sabiá utilizadas não prejudicaram a germinação das sementes de fava.
\end{abstract}

Palavras-chave - Alelopatia. Mimosa caesalpiniaefolia. Phaseolus lunatus. Germinação.

\begin{abstract}
The Mimosa caesalpiniaefolia Benth. is a medicinal plant that can be used in agroforestry systems, is also employed in the composition of pasture trees in strips between fields, to enrich brush fields and as a hedge. The Phaseolus lunatus L. is one of four species of the genus Phaseolus exploited commercially; its use is preferably in the form of green beans cooked or in canned form. The aim of the present research was to evaluate aqueous extracts of Mimosa caesalpiniaefolia on the germination of seeds and initial growth of broad beans seedlings. The seeds of bean were sowed into vermiculite in boxes and placed in a germinador at $25^{\circ} \mathrm{C}$ under continuous light. The substrate was moistened with the aqueous extract of young leaves of Mimosa caesalpiniaefolia in concentrations of $25 \% ; 50 \% ; 75 \%, 100 \%$, and a control treatament whose substrate was moistened only with distilled water. The parameters evaluated were: percentage, first count, the index of germination speed and length of the primary root. The experimental design was completely randomized design with four replications of 25 seeds each. The data were subjected to analysis of variance and regression polynomial. In the study of polynomial regression $(\mathrm{p}<0,05)$ equation was used to best fit the data. The values in percentage were transformed in $\operatorname{arc} \operatorname{sen}(\mathrm{n} / 100)^{0,5}$. It was concluded that different concentrations of extract of leaves of young Mimosa caesalpiniaefolia did not prevent germination of Phaseolus lunatus.
\end{abstract}

Key words - Allelopathy. Mimosa caesalpiniaefolia. Phaseolus lunatus. Germination.

\footnotetext{
* Autor para correspondência

${ }^{1}$ Recebido para publicação em 11/08/2009; aprovado em 20/07/2010

Pesquisa Financiada pela Universidade Federal Rural de Pernambuco

${ }^{2}$ Programa de Pós-Graduação em Ciências Florestais, DCF/UFRPE, Recife-PE, Brasil, egbsf@bol.com.br

${ }^{3}$ Departamento de Agronomia/UFRPE, Recife-PE, Brasil, vpmatos@ig.com.br, lumsena@bol.com.br

${ }^{4}$ Programa de Pós-Graduação em Ciências Florestais, DCF/UFRPE, Recife-PE, Brasil, seedsannaballet@yahoo.com.br
} 


\section{Introdução}

O sabiá (Mimosa caesalpiniaefolia Benth.) Leguminosae-Mimosoideae, pode serutilizado em sistemas agroflorestais, sendo também empregado na composição de pastagens arbóreas, em faixas entre plantações, para enriquecer capoeiras e ainda pode ser empregado como cerca viva (MAIA, 2004). É uma planta de rápido crescimento e ideal para reflorestamentos destinados a recompor áreas degradadas (GARCIA et al., 2002). Na medicina caseira é usada contra males estomacais das vias respiratórias e como cicatrizante, sendo a produção de mudas desta espécie feita por sementes (FIGUEIRÔA et al., 2005). Segundo Lorenzi (1998), o sabiá é uma espécie de ocorrência no Nordeste, na região da caatinga, do Maranhão à Bahia. Apesar da importância para a Região Nordeste, o conhecimento sobre essa leguminosa ainda é incipiente, principalmente quanto aos aspectos silviculturais e nutricionais (MOURA et al., 2006).

Segundo Santos et al. (2002), a fava (Phaseolus lunatus L.), também é conhecida vulgarmente como feijão-lima ou feijão-fava, sendo uma das quatro espécies do gênero Phaseolus que é explorada comercialmente. Embora sua utilização seja menor, a fava parece ter uma maior capacidade de adaptação que o feijão comum (SANTOS et al., 2002). No Brasil, o consumo humano é preferencialmente na forma de grãos verdes cozidos, enquanto nos Estados Unidos, um dos maiores produtores de fava do mundo, seu consumo é na forma de conserva (VIEIRA, 1992).

A alelopatia é definida como efeito prejudicial ou benéfico entre plantas por meio de substâncias químicas, chamadas de aleloquímicos lançadas no meio. As substâncias alelopáticas podem interferir na germinação de sementes e/ou estabelecimento e desenvolvimento de indivíduos vegetais próximos (FERREIRA, 2004; GATTI et al., 2007). Quando as sementes são submetidas a condições de toxicidade causada por alguma substância química, esse fator pode induzi-las a apresentarem dormência secundária (CARDOSO, 2004).

Os estudos sobre o conhecimento da ação alelopática de espécies nativas ainda é incipiente no Brasil, considerando-se a extensão territorial e a diversidade florística (FERREIRA et al., 1992 apud MARASHIMSILVA; AQUILA, 2006). No entanto, é de grande importância a ampliação desse conhecimento visto que, observações de campo permitiram levantar a hipótese de que poderia haver efeito alelopático do sabiá sobre as demais espécies vegetais prejudicando assim o estabelecimento das mesmas (PIÑA-RODRIGUES; LOPES, 2001). O que corrobora a pesquisa realizada por Piña-Rodrigues e Lopes (2001) onde as diferentes concentrações de extratos de sabiá (Mimosa caesalpiniaefolia Benth.) apresentaram efeito tóxico sobre a germinação das sementes de ipê amarelo (Tabebuia alba (Cham.) Sandw.

De acordo com Rice, (1987) e Rodrigues et al., (1993) citado por Souza Filho et al. (2005), a utilização de espécies com propriedades alelopáticas assume aspectos ecológico e ambiental importantes em face da possibilidade dos aleloquimicos produzidos serem liberados para o ambiente pelas diferentes formas reconhecidas pela ciência, como lixiviação, exsudação radicular, volatilização e decomposição, com isso afetando a germinação das sementes (SOUZA FILHO et al., 2005).

No entanto há necessidade de maiores estudos, com relação à associação de espécies em plantios mistos, como vem sendo desenvolvido no Brasil nas associações agroflorestais ou silvopastoris, o que facilitaria a tomada de decisões na escolha de espécies em futuras associações (BORGES et al., 1994). Considerando que é necessária a recuperação de áreas degradadas e o possível uso do sabiá em sistemas agroflorestais, objetivou-se com esse trabalho, verificar o efeito das concentrações do extrato foliar aquoso do sabiá sobre a germinação de sementes e o crescimento inicial de plântulas de fava.

\section{Material e métodos}

As sementes de fava, cultivar Branquinha, obtidas em feira livre localizada na cidade de Recife-PE, foram submetidas ao efeito do extrato foliar aquoso de folhas jovens de sabiá. Os materiais utilizados para obtenção dos extratos aquosos foram coletados de árvores de sabiá, localizadas no Campus da Universidade Federal Rural de Pernambuco (UFRPE), Recife-PE e conduzidos ao Laboratório de Sementes do Departamento de Agronomia da UFRPE, onde foi realizado o experimento.

$\mathrm{O}$ extrato aquoso foi obtido a partir de duzentos gramas de folhas jovens de sabiá que foram cortadas em pequenos pedaços e trituradas em liquidificador, com 300 $\mathrm{ml}$ de água destilada a $80^{\circ} \mathrm{C}$. Em seguida, a mistura foi filtrada e acrescentou-se, mas $700 \mathrm{ml}$ de água obtendo-se o extrato concentrado a $100 \%$, do qual foram realizadas diluições para obtenção das demais concentrações.

As sementes de fava foram postas para germinar em caixas plásticas transparentes de $11 \times 11 \times 3 \mathrm{~cm}$ com tampa, semeadas entre o substrato vermiculita umedecido com $90 \%$ da sua capacidade de retenção de água que foi de aproximadamente $75 \mathrm{~mL}$ do extrato aquoso nas seguintes concentrações: $25 ; 50 ; 75$ e $100 \%$ e a testemunha (umedecida apenas com água destilada). Posteriormente as caixas plásticas foram 
levadas para germinador do tipo Biochemical Oxigen Demand (B.O.D.), regulado à temperatura constante de $25{ }^{\circ} \mathrm{C}$ e regime de luz contínua.

As variáveis avaliadas foram: porcentagem de germinação - que correspondeu à porcentagem total de sementes germinadas até o término do experimento, isto é $8^{\circ}$ dia após a semeadura; primeira contagem da germinação - correspondeu à porcentagem de sementes germinadas no $5^{\circ}$ dia após a semeadura; índice de velocidade de germinação - calculado de acordo com a fórmula apresentada por Maguire (1962) e comprimento da raiz principal - no final do teste de germinação, as raízes principais das plântulas normais de cada repetição foram medidas com auxílio de uma régua graduada em centímetros, sendo os resultados expressos em centímetros por plântula. Adotou-se como critério de germinação o surgimento do hipocótilo e a conseqüente emergência dos cotilédones.

O delineamento experimental utilizado foi $\mathrm{o}$ inteiramente casualizado, com quatro repetições de 25 sementes cada. Os dados obtidos foram submetidos à análise de variância e as médias foram comparadas pelo teste de Tukey a $5 \%$ de probabilidade, sendo que os dados em porcentagem foram transformados em arc sen $(\mathrm{n} / 100)^{0,5}$. Para realização da análise foi utilizado o software estatístico ESTAT, versão 2.0 (ESTAT, 1994) desenvolvido pela FCAV/UNESP.

\section{Resultados e discussão}

$\mathrm{O}$ teste $\mathrm{F}$ da análise de variância revelou que os efeitos significativos entre os tratamentos ocorreram nos parâmetros primeiros contagem, índice de velocidade de germinação e comprimento da raiz (Tabela 1).

Como pode ser observado na Figura 1, não houve diferença significativa entre as concentrações do extrato aquoso de folhas jovens de sabiá, sobre a germinação das sementes de fava. Isso evidencia que as diferentes concentrações do extrato não foram eficientes para causar efeito alelopático sobre a germinação dessas sementes. Piña-Rodrigues e Lopes (2001) verificaram que altas concentrações (1:8) de extratos de folhas verdes de sabiá não inibiram a porcentagem de germinação de sementes de ipê-amarelo (Tabebuia alba (Cham) Sandw.) mas causou efeito alelopático a medida que retardou a germinação das sementes em relação a testemunha. De acordo com Marashim-Silva e Aquila (2006) a germinação dos aquênios de alface (Lactuca sativa L.) submetidos ao extrato foliares de cinco espécies (Cecropia pachystachya, Peltophorum dubium, Psychotria leiocarpa, Sapium glandulatum e Sorocea bonplandii) não mostrou diferença significativa em relação ao tratamento controle durante 96 horas. Segundo Ferreira (2004) a germinação é menos sensível a substâncias alelopáticas do que o crescimento da plântula.

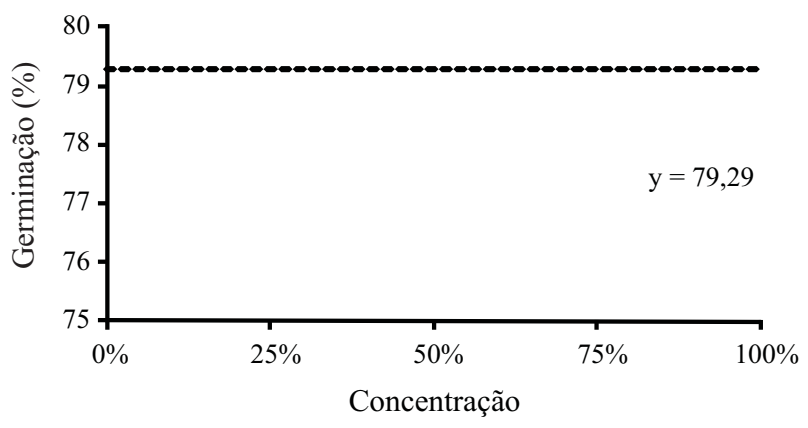

Figura 1 - Porcentagem de germinação de sementes de fava submetidas a diferentes concentrações de extrato aquoso de folhas jovens de sabiá

Com relação à primeira contagem de germinação de sementes de fava (FIG. 2), os maiores valores foram obtidos quando se utilizou o extrato aquoso de folhas jovens de sabiá na concentração de 50 e $100 \%$. Menor germinação foi verificada quando foi utilizada a concentração $0 \%$ (testemunha) que não diferiu da concentração de 25 e $75 \%$ do extrato aquoso do sabiá. Em trabalhos realizados com sementes de alface, a

Tabela 1 - Resumo da análise de variância da germinação, primeira contagem e índice de velocidade de germinação das sementes e comprimento da raiz de plântulas de fava submetidas a diferentes concentrações de extrato aquoso de folhas jovens de sabiá

\begin{tabular}{ccccc}
\hline & \multicolumn{4}{c}{ Quadrados Médios } \\
\hline Fontes de Variação & Germinação & Primeira contagem & IVG & Comprimento da raiz \\
\hline Tratamentos (T) & $62,4421^{\mathrm{NS}}$ & $267,0940^{* *}$ & $4,2963^{*}$ & $4,6998^{* *}$ \\
Resíduo (R) & $80,3883^{\mathrm{NS}}$ & $33,7651^{* *}$ & $0,9763^{*}$ & $0,4521^{* *}$ \\
\hline C.V.(\%) & 11,31 & 11,81 & 12,56 & 19,03 \\
\hline
\end{tabular}


concentração $0 \%$ de extrato aquoso de aroeira (Schinus terebinthifolius Raddi) com fervido e não fervido foi a que proporcionou melhor resultado de primeira contagem de germinação (SOUZA et al., 2007).

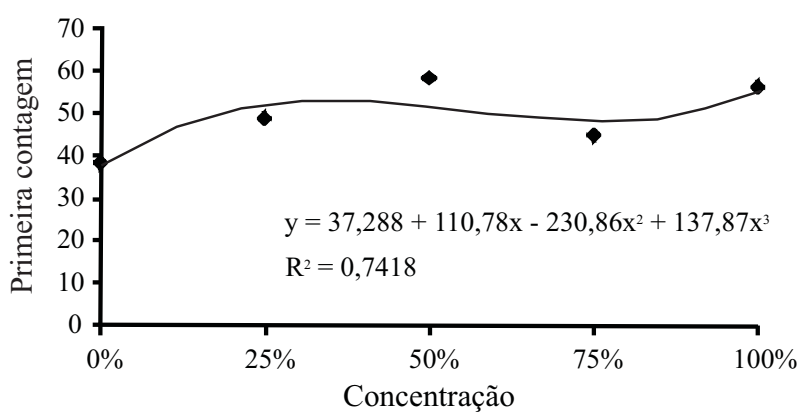

Figura 2 - Primeira contagem da germinação de sementes de fava submetidas a diferentes concentrações de extrato aquoso de folhas jovens de sabiá

Para o índice de velocidade de germinação foi observado que não houve efeitos significativos de ordem linear, quadrática e cúbica entre as concentrações (FIG. 3). Já para sementes de sorgo (Sorghum bicolor (L.) Moench), as diferentes concentrações do extrato aquoso do sabiá não causaram decréscimo na velocidade de germinação das mesmas (SENA et al., 2006). Também não houve efeito algum, das diferentes soluções de solo testadas sobre o índice de velocidade de germinação das sementes de alface (MARTINS et al., 2006). Os resultados do trabalho realizado por Piña-Rodrigues e Lopes (2001) indicaram a presença de toxidez e, possivelmente, potencial de alelopatia promovida pelas folhas verdes recém-caídas de sabiá, onde este efeito se manifestou através da redução da velocidade ou inibição da germinação das sementes de ipê-amarelo (Tabebuia alba (Cham.) Sandw).

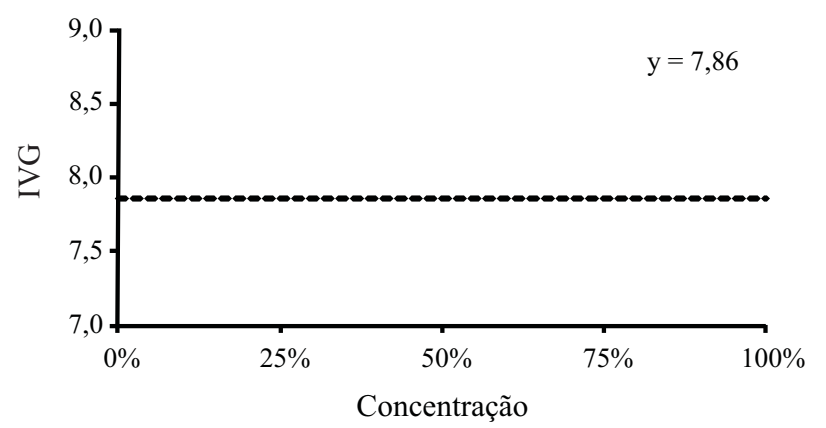

Figura 3 - Índice de velocidade de germinação (IVG) de sementes de fava submetidas a diferentes concentrações de extrato aquoso de folhas jovens de sabiá
Observa-se na Figura 4 uma diminuição do comprimento da raiz de plântulas de fava nas concentrações 25 e $75 \%$, quando comparadas com a testemunha. Verificou-se também crescimento da raiz de plântulas de fava na concentração de 100\% embora não diferindo da testemunha. Possivelmente esta concentração do extrato aquoso apresentou efeito promissor no crescimento da raiz, favorecendo a multiplicação e diferenciação celular. Substâncias alelopáticas liberadas em quantidades suficientes podem causar inibição ou estimulação da germinação, do crescimento da planta (CARVALHO, 1993 apud GOLDFARB et al., 2009) e do sistema radicular.

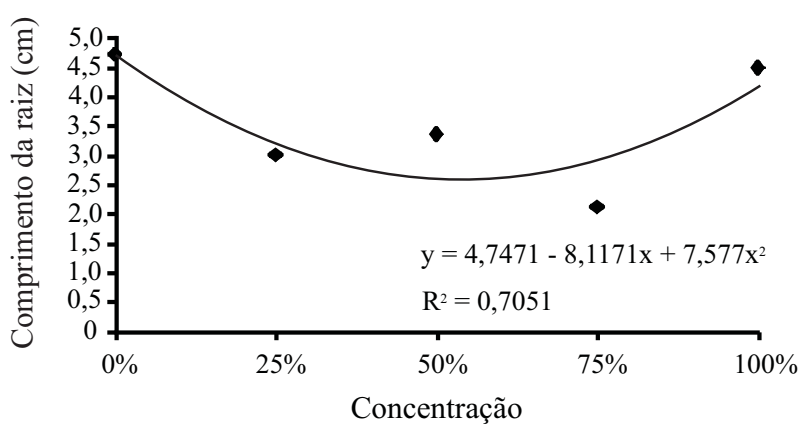

Figura 4 - Comprimento da raiz principal de plântulas de fava submetidas a diferentes concentrações de extrato aquoso de folhas jovens de sabiá

Segundo Alves et al. (2004) o extrato volátil de óleo essencial de jaborandi (Pilocarpus microphyllus Stapf. ex. Wardleworht) possui efeito alelopático benéfico, pois estimula o crescimento da radícula de plântulas de alface. Já em gergelim (Sesamun indicum L.) o crescimento radicular das plântulas foi significativamente reduzido na presença do triturado de folhas de Solanum lycocarpum A. St.-Hil. (AIRES et al., 2005) assim como nas plântulas de beijo-de-frade (Impatiens balsamina Hooker F.), o sistema radicular também foi a parte vegetal mais afetada pela presença do extrato de folhas de tiririca (Cyperus rotundus L.) (PORTILHO et al., 2007).

Em alguns parâmetros avaliados as concentrações do extrato aquoso do sabiá ocasionaram resultados superiores ao da testemunha, no entanto observa-se que não houve efeito inibidor da germinação de sementes de fava, assim como no desenvolvimento das plântulas já que a maior concentração (100\%) apenas diferiu da testemunha na primeira contagem da germinação. Dessa forma, os resultados do presente trabalho indicam que a sabiá pode ser utilizado em sistemas agroflorestais. 


\section{Conclusão}

Conclui-se que as diferentes concentrações do extrato de folhas jovens de sabiá utilizadas não prejudicaram a germinação das sementes de fava.

\section{Agradecimentos}

Os autores agradecem ao REUNI/CAPES pela bolsa de Doutorado do primeiro autor e ao $\mathrm{CNPq}$ pela bolsa de iniciação científica do penúltimo autor.

\section{Referências}

AIRES, S. S.; FERREIRA, A. G.; BORGHETTI, F. Efeito alelopático de folhas e frutos de Solanum lycocarpum A. St.-Hil. (Solanaceae) na germinação e crescimento de Sesamun indicum L. (Pedaliaceae) em solo sob três temperaturas. Acta Botânica Brasílica, v. 19, n. 02, p. 339-344, 2005.

ALVES, M. C. S. et al. Alelopatia de extratos voláteis na germinação de sementes e no comprimento da raiz de alface. Pesquisa Agropecuária Brasileira, v. 39, n. 11, p. 1083-1086, 2004.

BORGES, E. E. L.; SILVA, G. F.; LOPES, E. S. Avaliação de substâncias alelópaticas em vegetação de uma floresta secundária. Revista Árvore, v. 18, n. 03, p. 275-286, 1994.

CARDOSO, V. J. M. Dormência: estabelecimento do processo. In: FERREIRA, G.; BORGHETTI, F. Germinação: do básico ao aplicado. Porto Alegre: Artmed, 2004. cap. 5, p. 95-108.

FERREIRA, A. G. Interferência: competição e alelopatia. In: FERREIRA, A. G.; BORGHETTI, F. Germinação: do básico ao aplicado. Porto Alegre: Artmed, 2004. cap. 16, p. 251-262.

FIGUEIRÔA, J. M. et al. Madeiras. In: SAMPAIO, E. V. S. B. et al. Espécies da flora nordestina de importância econômica potencial. Recife: Associação Plantas do Nordeste, 2005. 327 p.

GARCIA, J.; DUARTE, J. B.; FRASSETO, E. G. Superação de dormência em sementes de sansão-do-campo (Mimosa caesalpiniaefolia L.). Pesquisa Agropecuária Tropical, v. 32, n. 01, p. 29-31, 2002.

GATTI, A. B.; PEREZ, S. C. J. G. A.; FERREIRA, A. G. Avaliação da atividade alelopática de extratos aquosos de folhas de espécies de cerrado. Revista Brasileira de Biociências, v. 05, p. 174-176, 2007. Suplemento 02.

GOLDFARB, M.; PIMENTEL, L. W.; PIMENTEL, N. W. Alelopatia: relações nos agroecossistemas. Tecnologia \& Ciência Agropecuária, v. 03, n. 01, p. 23-28, 2009.
LORENZI, H. Árvores brasileiras: manual de identificação e cultivo de plantas arbóreas nativas do Brasil. Nova Odessa: Plantarum, 1998. p. 351.

MAGUIRE, J. D. Speed of germination-aid in selection and evaluation for seedlings emergence and vigor. Crop Science, v. 02, n. 01, p. 176-177, 1962.

MAIA, G. N. Caatinga: árvores e arbustos e suas utilidades. São Paulo: D\&Z Computação gráfica e editora, 2004. p. 333-341.

MARASCHIN - SILVA, F.; AQUILA, M. E. A. Potencial alelopático de espécies nativas na germinação e crescimento inicial de Lactuca sativa L. (Asteraceae). Acta Botânica Brasílica, v. 20, n. 01, p. 61-69, 2006.

MARTINS, D.; MARTINS, C. C.; COSTA, N. V. Potencial alelopático de soluções de solo cultivado com Brachiaria brizantha: efeitos sobre a germinação de gramíneas forrageiras e plantas daninhas de pastagens. Planta Daninha, v. 24, n. 01, p. 61-70, 2006.

MOURA, O. N. et al. Distribuição de Biomassa e nutrientes na parte aérea de Mimosa caesalpiniaefolia Benth. Revista Árvore, v. 30, n. 06 , p. 877-884, 2006.

PIÑA-RODRIGUES, F.C. M.; LOPES, B. M. Potencial alelopático de Mimosa caesalpinaefolia Benth sobre sementes de Tabebuia alba (Cham.) Sandw. Floresta e Ambiente, v. 08, n. 01, p. 130-136, 2001.

PORTILHO, G. P. et al. Alelopatia de extratos aquosos de Cyperus rotundus L. sobre a germinação e estabelecimento de Impatiens balsamina Hooker F. Revista Científica da Faminas, v. 03, n. 01, p. 249, 2007.

SANTOS, D. et al. Produtividade e morfologia de vagens e sementes de variedades de fava no Estado da Paraíba. Pesquisa Agropecuária Brasileira, v. 37, n. 10, p. 1407-1412, 2002.

SENA, L. H. M. et al. Efeito de diferentes concentrações do extrato aquoso do sabiá (Mimosa caesalpiniaefolia Benth.) sobre a germinação de sementes de Sorghum bicolor (L.) Moench. In: SEMINÁRIO PANAMERICANO DE SEMENTES, 20., 2006, Fortaleza. Anais... Fortaleza: CESM, 20061 CD-ROM.

SOUZA, C. S. M. et al. Alelopatia do extrato aquoso de folhas de aroeira na germinação de sementes de alface. Revista Verde de Agroecologia e Desenvolvimento Sustentável, v. 02, n. 02, p. 96-100, 2007.

SOUZA FILHO, A. P. S.; FONSECA, M. L.; ARRUDA, M. S. P. Substâncias químicas com atividades alelopáticas presentes nas folhas de Parkia pendula (Leguminosae). Planta Daninha, v. 23 , n. 04 , p. $565-573,2005$.

VIEIRA, R. F. A. A cultura do feijão - fava. Informe Agropecuário, v. 16, n. 174, p. 30-37, 1992. 